\title{
Ruptured tubal pregnancy in an undiagnosed heterotopic pregnancy
}

\author{
Sunil K. Juneja, Pooja Tandon*, Bakul Kochhar, Monika Narang, Manisha Badan
}

Department of Obstetrics \& Gynaecology, Dayanand Medical College and Hospital, Ludhiana, Punjab, India

Received: 08 March 2016

Accepted: 04 April 2016

\section{*Correspondence:}

Dr. Pooja Tandon,

E-mail: drpoojatandon77@yahoo.com

Copyright: (c) the author(s), publisher and licensee Medip Academy. This is an open-access article distributed under the terms of the Creative Commons Attribution Non-Commercial License, which permits unrestricted non-commercial use, distribution, and reproduction in any medium, provided the original work is properly cited.

\section{ABSTRACT}

Heterotopic pregnancy is rare obstetrical emergency the diagnosis of which is usually delayed. A high degree of suspicion is required to diagnose to reduce maternal morbidity and mortality. At the same time salvage of the intrauterine pregnancy can be done.

Keywords: Ruptured, Heterotopic pregnancy

\section{INTRODUCTION}

Heterotopic pregnancy refers to the presence of simultaneous occurrence of two or more implantation sites. Most often these sites are a combination of intrauterine and ectopic pregnancies, rather than two ectopic pregnancies. ${ }^{1}$ Heterotopic pregnancy is rare, estimated to occur in 1 in 30,000 pregnancies ${ }^{1 .}$ The incidence of heterotopic pregnancy has been increased to approximately 1 in 3900 pregnancies because of increasing pelvic inflammatory disease, administration of ovarian stimulation agents, and use of assisted reproductive techniques (ART). ${ }^{2}$ The clinical features of heterotopic pregnancies closely mimic the symptoms of threatened abortion which include abdominal pain, adnexal mass, peritoneal irritation, and an enlarged uterus; these patients are diagnosed at late gestational age because when an intrauterine gestation is observed on ultrasound, the possibility of an extra ectopic pregnancy is generally not considered. ${ }^{3}$

\section{CASE REPORT}

A 23 year old $\mathrm{G}_{3} \mathrm{~A}_{2} \mathrm{P}_{0}$ at 15 weeks amenorrhea presented in emergency with hemoperitoneum and shock. Ultrasound showed both intrauterine and extra uterine pregnancy. A single live fetus of 14 weeks 4 days gestation with normal cardiac and somatic activity was seen in the uterine cavity. Placenta was fundo-anterior. There was an extra uterine left adnexal pregnancy of 14 weeks 4days gestation. Cardiac activity not appreciated. Moderate amount of free fluid was seen in pouch of douglas. Patient was diagnosed to be having heterotopic pregnancy with ruptured left ectopic pregnancy and was taken for emergency laparotomy. Intraoperatively left fallopian tube was found ruptured with fetus of around 12 to 14 weeks period of gestation and placenta lying in abdominal cavity. About three litters of blood and $300 \mathrm{~g}$ of clot removed. Left fallopian tube excised and sent for histopathology. Abdominal drain put and abdomen closed in layers. Post operatively ultrasound showed a single intrauterine pregnancy of 14 weeks 6days with normal cardiac activity. Postoperative period was uneventful. Drain removed after three days. Patient discharged after five days in a satisfactory condition.

\section{DISCUSSION}

Heterotopic pregnancy is difficult to diagnose. Incidence of spontaneous heterotopic pregnancies is low but increased frequency is seen with ART pregnancies. ${ }^{4}$ Most cases present with tubal ectopic but cervical and ovarian pregnancies are also being reported. ${ }^{5,6}$ Many go unnoticed and a high index of suspicion should be kept for timely diagnosis and treatment especially in assisted reproductive techniques. Absent vaginal bleeding in presence of other signs and symptoms of ectopic pregnancy along with abnormally high beta hCG levels should raise suspicion. ${ }^{7}$ Other suggestive points can be persistently raised beta hCG levels after dilatation and curettage, uterine fundal height more than period of 
gestation or more than one corpus luteum seen in ultrasound. Normal intrauterine gestation with haemorrhagic corpus luteum can simulate heterotopic gestation. ${ }^{8}$ Other causes of acute abdomen in pregnancy should be ruled out. High resolution ultrasound and beta hCG levels are helpful in establishing the diagnosis. Doppler shows increased flow in adnexa with low resistance index. ${ }^{4}$ Treatment is laparoscopy/laparotomy for ectopic pregnancy with close monitoring of intrauterine pregnancy. Diagnosing a heterotopic pregnancy requires high index of suspicion especially in ART pregnancies. Timely intervention can salvage the intrauterine pregnancy. ${ }^{8}$

Funding: No funding sources

Conflict of interest: None declared

Ethical approval: Not required

\section{REFERENCES}

1. Talbot K, Simpson R, Price N, Jackson SR. Heterotopic pregnancy. J Obstet Gynaecol. 2011;31:7-12

2. Tal J, Haddad S, Gordon N, Timor-Tritsch I. Heterotopic pregnancy after ovulation induction and assisted reproductive technologies: A literature review from 1971 to 1993. Fertil Steril. 1996;66:112.

3. Hassiakos D, Bakas P, Pistofidis G, Creatsas G. Heterotopic pregnancy at 16 weeks of gestation after in-vitro fertilization and embryo transfer. Arch Gynecol Obstet. 2002;266:124-5.

4. Glassner MJ, Aron E, Eskin BA. Ovulation induction with clomiphene and rise in hetrotopic pregnancies. J Reprod Med. 1990;35:175-8.

5. Hirose $M$, Nomura $T$, Wakuda $K$, Ishguro $T$, Yoshida Y. Combined intrauterine and ovarian pregnancy: A case report. Asia Ocaena J Obstet Gynaecol. 1994;20:25.

6. Peleg D, Bar-Hava I, Neaman-Leavin M, Ashkena, Ben-Rafaelz IJ. Early diagnosis and successful nonsurgical treatment of viable combined intrauterine and cervical pregnancy. Fertil Steril. 1994;62:405.

7. Sohail S. Haemorrhagic corpus luteum mimicking heterotopic pregnancy. J Coll Physicians Surg Pak. 2005;15:180-1.

8. Espinosa PM, Alcantar Mendoza MA. Heterotopic pregnancy: Report of a case and review of literature Ginecol Obstet Mex. 1997;65:482-6.

Cite this article as: Juneja SK, Tandon $\mathrm{P}$, Kochhar B, Narang M, Badan M. Ruptured tubal pregnancy in an undiagnosed heterotopic pregnancy. Int J Reprod Contracept Obstet Gynecol 2016;5:1675-6. 